\title{
Poesía y género: de la tradición puertorriqueña del macho impotente a la feminización subversiva niuyorriqueña ${ }^{1}$.
}

\section{Resumen}

Este trabajo aborda la tradición literaria puertorriqueña de la impotencia y su tratamiento de género en el ámbito de la poesía niuyorriqueña, tradición que recupera un legado puertorriqueño falocéntrico (Algarín, Esteves) pero que al mismo tiempo introduce una superación del mismo por medio de la potencia subversiva de su feminización (Laviera).

Palabras claves

Poesía niuyorriqueña - Poesía puertorriqueña - Literatura Latina de EEUU - Estudios Género Feminización.

\begin{abstract}
This paper focuses on the Puerto Rican literary tradition of impotence and its treatment of gender in the field of nuyorican poetry, a tradition that recovers a phallocentric Puerto Rican heritage (Algarín, Esteves) but at the same time introduces an overcoming of it through the subversive power of its feminization (Laviera).

Keywords

Nuyorican Poetry - Puerto Rican Poetry - Latino Literature - Gender Studies - Feminization.
\end{abstract}

\footnotetext{
${ }^{1}$ Este artículo amplía algunos conceptos sobre la relación entre cuerpo e identidad en la literatura niuyorriqueña presentados en las III Jornadas del Centro Interdisciplinario de Investigaciones en Género (La Plata-Argentina, septiembre de 2013). Disponible en $<$ http://www.memoria.fahce.unlp.edu.ar/trab eventos/ev.3417/ev.3417.pdf $>$.
} 
CATEDRAL TomAdA: Revista de crítica literaria latinoamericana / Journal of Latin American Literary Criticism

Poesía y género: de la tradición puertorriqueña del macho impotente a la feminización subversiva niuyorriqueña

\section{El singular caso de un canon afeminado: la tradición puertorriqueña de la impotencia.}

“¿Qué pasaría si en una "nación” colonial como Puerto Rico -en ese estado queer de libertad dependiente, de una nación sin nacionalidad ni soberaníala impotencia y la carencia fueran el único arma, el ardid supremo?" (CruzMalavé 140, mi traducción). Esta preguntaba guiaba el análisis del crítico puertorriqueño Arnaldo Cruz-Malavé en su estudio de la representación de la homosexualidad en la literatura puertorriqueña y su funcionalidad en la configuración de un singular canon "emasculado" dentro de las letras latinoamericanas; y es esta misma pregunta la que nos servirá como disparador en nuestro análisis de la relación entre poesía y género en la tradición literaria niuyorriqueña.

La conformación de los cánones literarios y su relación con la gestación de las identidades nacionales ha sido objeto de una profusión de estudios que, partiendo de los vínculos inmanentes entre la nación y su narración (Bhabha 1990), exponen la productividad de los significantes imaginarios como núcleos privilegiados en la institución de lo social (Castoriadis 2007), es decir, en la constitución de esas comunidades imaginadas (Anderson 1993) sobre las que se asientan las identidades nacionales. Tal como ha analizado Doris Sommer en su difundido ensayo Foundational Fictions: The National Romances of Latin America (1991), la novela latinoamericana cumplió a lo largo del siglo XIX la función de narrar las incipientes nacionalidades del continente al tiempo que configuraba los imaginarios cristalizados alrededor de estas todavía precarias identidades nacionales. Pero así como puede hablarse de una tradición y un canon latinoamericano abocado a sostener el andamiaje de estos procesos identitarios decimonónicos, del mismo puede rastrearse puntos de singularidad dentro de este marco, tal el caso de la literatura puertorriqueña y su particular modo de constituir una tradición literaria alrededor de una nación eternamente inconclusa. 
La sempiterna condición colonial de Puerto Rico, con su legado imperial hispánico y su presente neo-colonial norteamericano, definió su excepcional condición de nación sin soberanía, un estatus político que definió el dilema cultural puertorriqueño y su insoslayable obsesión por definir la posibilidad de establecer una identidad nacional bajo la condición de tal carencia ${ }^{2}$. Es bajo esta mirada obsesionada por la posibilidad de alcanzar una identidad nacional bajo la prerrogativa de la des-nacionalización colonial del régimen político puertorriqueño que el ensayo de Arnaldo Cruz-Malavé encuentra en la homosexualidad una de las claves de este proceso identitario puertorriqueño a lo largo de su historia, empezando por la figura canónica de Antonio S. Pedreira (1899-1939), una de las voces fundadoras de la literatura de Puerto Rico y cuyo ensayo Insularismo: Ensayos de interpretación puertorriqueña (1934) ahondó en esta condición emasculada de la identidad puertorriqueña, la cual, según Pedreira, arrastra una cadena histórica de sumisiones que junto al influjo de las condiciones raciales y geográficas, forzaron y configuraron su condición subalterna ${ }^{3}$, sumisa y dócil (su "aplatanamiento" en palabras de Pedreira), sentando así las bases de una interpretación de la identidad nacional a partir de su condición "afeminada" e invirtiendo, por tanto, el valor productivo de la virilidad como género privilegiado en la configuración narrativa de la nación dentro de esa tradición latinoamericana analizada por Sommer.

En esta articulación entre el género masculino y el género novela, ambos privilegiados en la orquestación de los cánones nacionales latinoamericanos, la condición colonial puertorriqueña supuso un punto de complejización de la identidad masculinizada de la patria, ese territorio-hembra donde la identidad nacional penetra para declarar su soberanía territorial, lingüística, cultural y política. Como señala el propio Cruz-Malavé la cultura puertorriqueña lidió con

${ }^{2}$ Cf. Cruz-Malave (1995); Díaz Quiñones (2000); Duany (2002); Grosfoguel (1997) y Ríos Ávila (2002).

${ }^{3}$ Utilizo el concepto de subalternidad y sujeto subalterno siguiendo la definición de Ranajit Guha como término que da "un nombre para el atributo general de la subordinación... ya sea que ésta esté expresada en términos de clase, casta, edad, género y oficio o de cualquier otra forma" (Guha $35)$. 
CATEDRAL TomAdA: Revista de crítica literaria latinoamericana / Journal of Latin American Literary Criticism

Poesía y género: de la tradición puertorriqueña del macho impotente a la feminización subversiva niuyorriqueña

este problema nacional durante el siglo XX por medio de la configuración paradójica de una tradición literaria que proyectaba la aspiración de la burguesía puertorriqueña de la década del 30 (tensada entre la imposibilidad política de constituir una nación independiente y la voluntad clara de no renunciar al mercado económico mayoritario constituido por los Estados Unidos) de proyectar un proceso de configuración identitaria a expensas de la soberanía y asentado, en cambio, en el terreno cultural. Canonizado por la obra de Pedreira y de esa otra figura tutelar de las letras puertorriqueñas como es René Marqués (1919-1979), este hegemónico discurso cultural puertorriqueño volvió, paradójicamente, hacia el discurso paternalista de los hacendados del siglo XIX por medio del significante imaginario de "la gran familia puertorriqueña" y su régimen patriarcal. Pero este canon se centró, antes que en la constitución de la nación, en la perversidad polimorfa de su intrascendente condición juvenil, condición perpetua cuya imposibilidad de acceder a la mayoría de edad merced a su estatus colonial marcaba su idiosincrática "impotencia". Es a partir de este imaginario impotente de la nación que el género se vuelve de-generación y lo homosexual o afeminado, lo e-masculado en verdad, se instituye como el signo visible de lo nacional.

Cruz-Malavé (1995) analiza pormenorizadamente cómo la institución de este canon literario orquestado en Insularismo y en ensayos (El puertorriqueño dócil -1960-) y obras literarias ("En la popa hay un cuerpo reclinado" -1959-) de René Marqués, afirman la preeminencia de este afeminamiento nacional entendido como carencia de la virilidad masculina asociada a la potencia fálica del significante imaginario de la "Nación-Macho", y cómo este imaginario afeminado asentado en la primera mitad del siglo XX es refuncionalizado luego por la narrativa puertorriqueña a partir de la década del 70 y a través de obras como las de Luis Rafael Sánchez (1936-) y Manuel Ramos Otero (1948-1990), y más recientemente en figuras como Mayra Santos Febres (1966), obras que inscriben una voz que desde este medio patológico de castración y entrecruzamiento de géneros, de ambigüedad e impotencia, optan, en cambio, por 
figuras marginales como la de la "loca" o la "drag queen" para narrar la identidad nacional, asumiendo esta condición abyecta no como mera celebración de lo noidentitario o de la hibridez, sino reposicionando la figura de lo abyecto al servicio de nuevas estrategias y nuevos contextos de resistencia cultural en el marco de esa red inextricable que atrapa a la cultura puertorriqueña en el debate irresoluto sobre su misma posibilidad de ser.

Ahora bien, es nuestra intención analizar cómo se desarrolla esta tradición de la impotencia puertorriqueña y su tratamiento de género en el ámbito específico de la poesía (y más específicamente en la poesía niuyorriqueña), ya que si bien la institución del canon nacional se opera sobre todo por medio de la novela como género discursivo privilegiado en la configuración de esa virilidad asertiva de la identidad nacional, no menos cierto es que también se ha desarrollado este mismo proceso en el terreno de la poesía, género cuya configuración histórica quedó marcada durante la Modernidad occidental por el imaginario romántico que adscribía al discurso poético su "naturaleza" individual, intimista y sensible, asociada estrechamente con la construcción socio-cultural del género "femenino" y su disposición "natural" hacia lo grácil, lo sensorial y sentimental ${ }^{4}$, lo que produjo una suerte de identificación genérica entre poesía y feminidad, relación que, en verdad, antes que establecer una analogía entre el poeta como sujeto social y la mujer como sujeto biológico, centraba la relación entre la mujer y lo poético en sí, por cuanto lo femenino constituía la materia poética de un lenguaje que, no obstante, continuaba siempre circunscripto por su ética masculina: "poesía eres tú" declamaba el español Gustavo A. Bécquer, puesto que el poeta era, por supuesto, él mismo 5 .

Señala Susana Reisz de Rivarola en su estudio de la poesía femenina en Hispanoamérica que es, precisamente, el "testimonio de los estrechos vínculos

\footnotetext{
${ }^{4}$ Me refiero al imaginario cristalizado alrededor de la poesía como discurso social en la cultura popular, más allá de que este imaginario de raíz romántica haya sido ampliamente superado en la poesía moderna su peso, en tanto significante social imaginario, continúa vigente en la cultura occidental contemporánea.

5 Para una discusión sobre esta diferencia entre la feminidad de la escritura poética y la figura autoral femenina, ver el artículo de Nelly Richard «¿Tiene sexo la escritura?» (1994).
} 
CATEDRAL TomAdA: Revista de crítica literaria latinoamericana / Journal of Latin American Literary Criticism

Poesía y género: de la tradición puertorriqueña del macho impotente a la feminización subversiva niuyorriqueña

entre la construcción del género femenino en la sociedad burguesa y la programación de las mujeres para la melancolía" (37) lo que asienta la potencia de la voz poética femenina en el marco de los cánones literarios, los cuales empero se encuentran siempre orquestados a partir de las prerrogativas falocéntricas de la patriarcal cultura occidental. De allí que la relación entre la poesía como género literario con la feminidad como género biológico revista aristas diferentes a las expuestas por los cánones virilizantes de las narrativas fundacionales en América Latina.

Arnaldo Cruz-Malavé (1995) exponía cómo en la literatura puertorriqueña esta tradición nacional virilizada se travestía a partir de una inversión afeminada asentada en la impotencia y la sodomía para representar una nación inmadura merced a su sempiterna condición colonial, del mismo modo en la poesía puertorriqueña el imaginario poético nacional se halla atravesado por esta impotencia idiosincrática que antes que feminizar una supuesta virilidad impotente, da cuenta de una hibridez constitutiva de lo puertorriqueño que manifiesta la intersección y entrecruzamiento recurrente de los géneros, por medio de una escritura que lejos de ostentar de modo definido una imagen de lo masculino o lo femenino se exhibe, en cambio, como una escritura subjetivamente sexuada en la cual por sobre los condicionamientos biológico-sexuales y sociales del sujeto-autor, lo que prima son los cruces interdialécticos de sus múltiples fuerzas de subjetivación (Kristeva 1974). Esto implica para el caso de la literatura fundacional puertorriqueña la emergencia de una escritura en cuyo deseo proyectado por alcanzar la potencia asertiva del falo-nación vibra la condición incompleta de un presente signado por la impotencia de sus carencias y su consiguiente representación afeminada, entiéndase a-feminada y no feminizada, ya que en los textos fundacionales de Pedreira y Marqués (siendo este último homosexual) la perspectiva desde la cual se representa este atributo femenino de la identidad nacional puertorriqueña es eminentemente masculina, siendo, por consiguiente, lo femenino el reverso vacuo del deseo masculino, y de allí que la representación de este deseo por lo que se carece apele a lo $a$-feminado en tanto $e$ - 
masculado, insistiendo, particularmente, en los prefijos privativos de ambos términos ${ }^{6}$. Será recién con la obra de autores como Luis Rafael Sánchez y Manuel Ramos Otero y a partir de la década del setenta que lo femenino en tanto feminización (primacía de lo semiótico-pulsional por sobre la racionalización monológica del significado masculino, en términos de Julia Kristeva (1974) emerja como signo para la representación de la identidad nacional puertorriqueña.

Es, entonces, la conjunción sexual de estas dos representaciones genéricas la que define la ambigüedad del discurso nacional puertorriqueño, ambigüedad que caracteriza la cultura puertorriqueña a partir de esa dimensión intersticial (Bhabha 1994) que configura su condición de "Estado sin Nación", una situación política sobre la cual se forjó el otro extremo histórico de esta cultura intersticial: la diáspora a los Estados Unidos. De esta condición diaspórica e intersticial, la cual explica el hecho de que actualmente más de la mitad de los puertorriqueños vivan fuera de la isla (Duany 2003), surge un capítulo decisivo (y no menos solapado por ello) de la historia de Puerto Rico como es el de la emergencia de la cultura nuyorican o niuyorriqueña, neologismo con el que se designa a la cultura de la diáspora puertorriqueña en la ciudad de Nueva York, sede principal de la migración puertorriqueña a los Estados Unidos.

Es nuestro propósito en este trabajo analizar cómo la tradición poética niuyorriqueña ha recuperado el derrotero marcado por la literatura puertorriqueña insular para inscribir en el ámbito de la poesía el pasaje desde una representación falocéntrica de la identidad puerto/niuyorriqueña hacia una feminización, en términos kristevianos, orientada a resolver el dilema nacional puertorriqueño sobre la posibilidad de establecer una identidad sin contar con la soberanía de una Nación en la cual garantizar la misma. Nuestra lectura de la poesía niuyorriqueña identifica un momento fundacional inaugurado en la década del setenta, principalmente por medio de la labor instituyente de las figuras tutelares de

${ }^{6}$ Esta identificación diferencial de lo femenino como reverso y carencia de la asertividad masculina configura una ficción dominante proyectada sobre la castración simbólica en que se funda la masculinidad en tanto sistema de autoridad de la sociedad patriarcal. Ver: Silverman (1992). 
CATEDRAL TomAdA: Revista de crítica literaria latinoamericana / Journal of Latin American Literary Criticism

Poesía y género: de la tradición puertorriqueña del macho impotente a la feminización subversiva niuyorriqueña

Miguel Algarín (1941-) y Miguel Piñero (1946-1988), y su reproducción de la discursividad falocéntrica de la tradición insular de la impotencia puertorriqueña, para arribar luego a la superación de esta lógica masculina a través de la poética de la fruición postulada por el poeta Tato Laviera (1950-2013) y su elección de centrar la experiencia de la puerto/niuyorriqueñidad como identidad cultural en la potencia somática del cuerpo femenino mulato.

\section{La cuestión de género en la poesía niuyorriqueña: de machos impotentes y mujeres subalternas.}

En la primera generación poética niuyorriqueña la condición marginal y minoritaria de la comunidad puertorriqueña en los Estados Unidos adopta la forma de un discurso literario de acentuado tono agonístico y confrontativo. En esta tradición literaria fuertemente marcada por un compromiso político de corte sartreano $^{7}$, los poetas procuran dar cuenta de las miserias de la vida en los márgenes, marginalidad que repercute en la férrea voluntad de representar el espacio hostil que agrede y oprime al niuyorriqueño no sólo marginándolo socialmente, sino también a través de su clima extremo, sus tonalidades depresivamente grises y su arquitectura degradada, elementos que se contraponen directamente a la opuesta naturaleza afable y hospitalaria del idealizado espacio insular de Puerto Rico. Así, por ejemplo, en muchos poemas la insistencia en contraponer pleonasmos que giran alrededor del "cemento", los "edificios abandonados", el color "gris", los "callejones", el "frío", la "nieve", etc. funcionan antitéticamente a través de su binarismo con otros significantes poéticos que remiten a la naturaleza y al clima tropical de Puerto Rico, o bien establecen una oposición valorativa a través de distintas metáforas que reproducen esta polarización.

${ }^{7}$ Sobre las diversas modulaciones que adopta esta politicidad de la poesía niuyorriqueña, ver: López (2014). 
Es, entonces, dentro de esta tradición literaria contestataria y agonística que el cuerpo, en tanto espacio significativo privilegiado en las autofiguraciones y configuraciones identitarias ${ }^{8}$, ocupa un lugar central en tanto signo material de la condición subalterna de esta identidad minoritaria. Así, por ejemplo, en la obra de Miguel Algarín, miembro fundador y figura tutelar de este movimiento, la constitución de la identidad niuyorriqueña se configura a partir de su carácter subalterno y marginal en tanto sujeto oprimido dentro de un sistema clásico de explotación capitalista, pero insistiendo, enfática y específicamente, en su corporalidad sometida e impotente, tal como se puede apreciar en su difundido poema "A Mongo Affair":

they tell me they get money

and medical aid

that their rent is paid

that their clothes get brought

that their teeth get fixed

is that true?"

I have to admit that he has been

lied to, misled,

that I know that all the goodies

he named humiliate the receiver,

that a man is demoralized

when his woman and children

beg for weekly checks

that even the fucking a man does

on a government bought mattress

\footnotetext{
${ }^{8}$ Cf. Turner (1994) y Kogan (2007).
} 


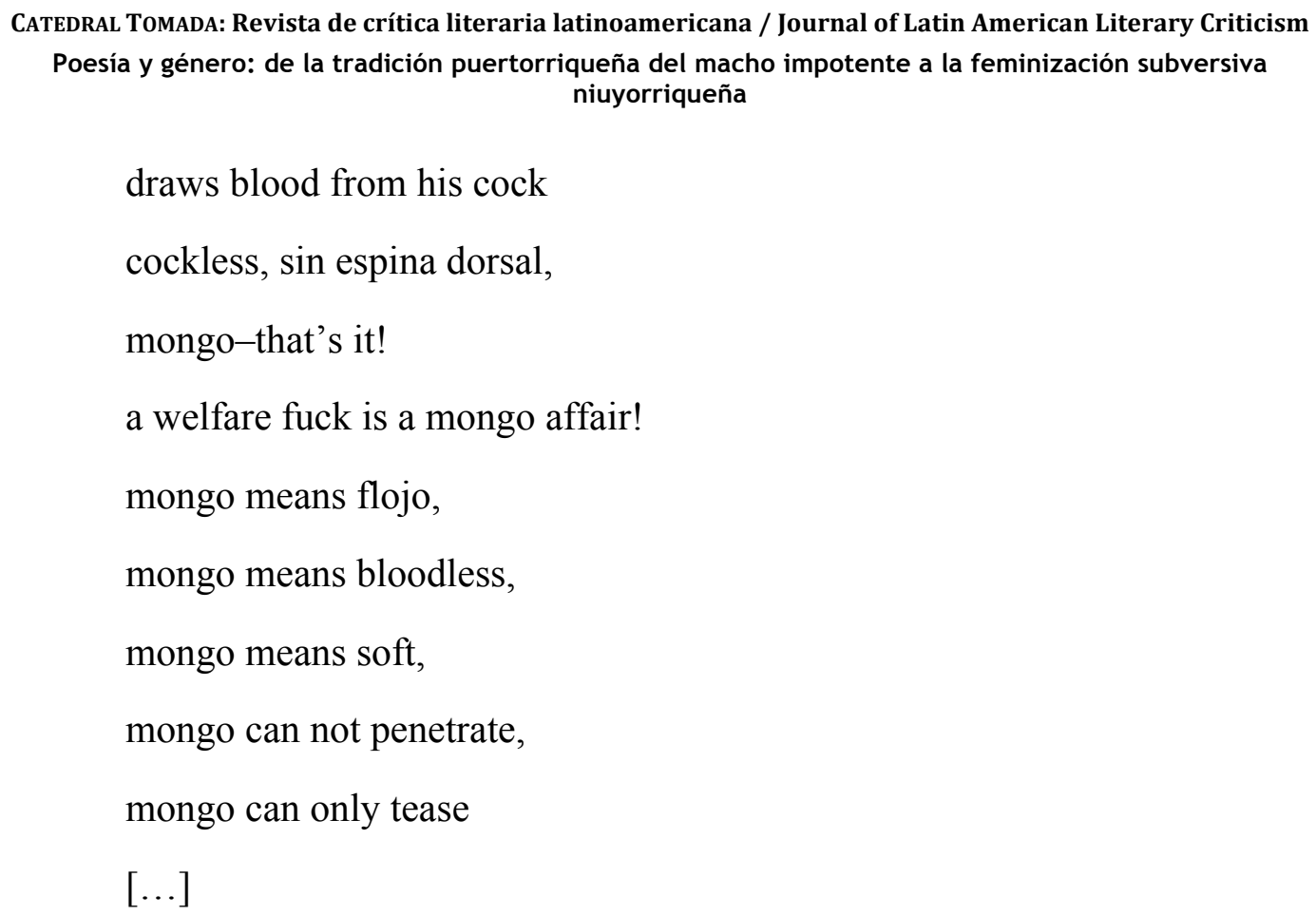

and when you whispered

your anger into my ears

when you spoke of

"nosotros los que estamos

preparados con las armas,"

it was talk of future

happiness... (Algarín, Survival 39-44)

La poética desplegada en el poema de Algarín configura una identidad niuyorriqueña a partir de su carácter desvalido y marginal, pero lo hace insistiendo, especialmente, en su corporalidad "impotente", en su estado subalterno en tanto macho castrado (des-virilizado en el sentido de su emasculación). El poema enfatiza los términos sexuales que apelan a la impotencia de este sujeto subalterno, a su estado de desahucio sexual y su esterilidad en tanto metonimia de su impotencia para enfrentar la opresión de la que es objeto, analogía que, por ejemplo, en el poema de Miguel Piñero "La 
Metadona Está Cabrona" se vuelve explícita a través de la conminación e imprecación directa que el yo poético dirige a este sujeto impotente y dócil frente a los poderes que lo oprimen:

... they call you a slop 'cause you nod out on the job

and your wood won $\mathrm{t}$ throb, it just flops ... flops ... flops ...

can't yell out ghettocide since you did abide \& signed

on the dotted line

to an agreement of shame who's to blame

but you,

you motherfuckin' lame ... (Algarín, Nuyorican 66)

Estos sujetos niuyorriqueños impotentes, desmoralizados y humillados emergen a través de la confrontación con un agente de opresión que claramente puede identificarse con los sectores hegemónicos de la sociedad norteamericana WASP $^{9}$ que los someten a ese estado de privación y sometimiento a través de su opresión económica, cultural, social y, como señalamos, sexual. La apelación a la virilidad, o más bien a su ausencia, de este sujeto subalterno funciona dentro del sistema patriarcal falocéntrico de la cultura latina como un instrumento de conminación/conmoción que apunta directamente a cuestionar el valor de este sujeto impotente, instigándolo a recuperar su hombría por medio de la lucha (sexual/social/política); una restauración de la virilidad y el honor perdidos que aparecía como una promesa en la enunciación colectiva de los versos de Algarín "nosotros los que estamos preparados con las armas", en los que la identificación entre el arma y el falo se vuelve inmediata. Este orden falocéntrico que ubica en la figura del macho latino el valor virilizado del coraje, el orgullo y la potencia insurgente frente a la opresión es común en la cultura niuyorriqueña y se ve

${ }^{9}$ Las siglas WASP son el acrónimo que designa a la cultura hegemónica norteamericana: White Anglo-Saxon Protestan (blanco, anglosajón y protestante). 
CATEDRAL TomAdA: Revista de crítica literaria latinoamericana / Journal of Latin American Literary Criticism

Poesía y género: de la tradición puertorriqueña del macho impotente a la feminización subversiva niuyorriqueña

reflejado en la poética contradiscursiva del período a través de su articulación exhortativa respecto a la necesidad de sublevarse frente a la dominación, explotación y marginalización de la comunidad dentro de la sociedad norteamericana.

Por su parte, la figura de la mujer dentro de este sistema queda supeditada a un rol subsidiario determinado por su biológica función reproductiva y su ética doméstica, no obstante lo cual voces disidentes emergen para establecer una polémica acendrada alrededor de estas figuraciones de lo femenino. Probablemente no haya figuras femeninas más importantes dentro de esta primera generación niuyorriqueña que las de las poetas Sandra María Esteves (1948-) y Luz María Umpierre (1947-), binomio que se ratifica si se tiene en cuenta que ambas protagonizaron durante la década del ochenta un trascendental y polémico diálogo poético centrado, precisamente, alrededor de las representaciones literarias de la mujer dentro de la tradición niuyorriqueña. Sandra María Esteves es una de las figuras fundadoras de la poesía niuyorriqueña, junto a Pedro Pietri, Víctor Hernández Cruz, Tato Laviera, y los ya mencionados Algarín y Piñero. Su obra se inscribe plenamente dentro de la tradición contestataria institucionalizada por Algarín durante la década del setenta, pero es, fundamentalmente, su poema "A la mujer borrinqueña" el que mayor impacto ha tenido dentro de esta generación en virtud de su representación estereotipada de la mujer como sujeto subalterno dentro del orden patriarcal que la relega al espacio cerrado del domos y a la función doméstica de la reproducción, crianza y soporte de la vida pública encarnada por el hombre, una esencialización de este imaginario femenino que también se observa en otros poemas suyos, como por ejemplo en "Fertile woman is moon", donde Esteves exalta y sacraliza la figura femenina a partir de su "fertilidad", construyendo así una feminidad cuyos atributos son subordinados a su función maternal y a su inmanente ética doméstica:

Fertile woman is fire and thunder 
The voice of justice bringing the people up

The new day

A new way to live

Breathing hope into our children's soul

Green

Green

Fertile woman is green

Sea of fertility

Creator of destiny

Fertile woman rise

Reaching to the sky that fills us with being

Fertile woman rise and harvest the earth

With natural creativity

Motion of majesty (Esteves 69)

Incluso la apelación al animismo de la religiosidad sincrética afroantillana funciona dentro de la sacralización femenina del poema a partir de la capacidad y la potencia progenitora de la mujer, de modo tal que la asociación entre el cuerpo de la mujer fértil y la tierra sólo establece este valor productivo como fuente de su consagración.

La poética de Esteves es compleja y no puede reducirse, ciertamente, a esta mera esencialización estereotipada de la identidad femenina, no obstante, su obra ha sido objeto de una difundida polémica (principalmente a través de su controversia con la poeta Luz María Umpierre) debido a estas construcciones discursivas de la identidad femenina niuyorriqueña ligadas a una representación esencialista de la mujer a partir de su condición de género. Para el crítico puertorriqueño Efraín Barradas, por ejemplo, el poema de Esteves "Fertile woman 
is moon" evita caer en el estereotipo de la feminidad a través de la apelación a las divinidades afro-caribeñas, lo cual entrañaría, según Barradas, "un rechazo de las ideas y los ideales de la sociedad opresora por los oprimidos" (160). Sin embargo, aun cuando la religiosidad afro-antillana pueda funcionar como elemento contradiscursivo dentro del sistema socio-cultural hegemónico, en el poema la sacralización del cuerpo femenino no logra eludir el estereotipo centrado en su cualidad progenitora. El poema más paradigmático de esta representación esencialista de la identidad femenina y su corporalidad reproductiva es, como ya señalamos, "A la mujer borrinqueña", poema en el cual Esteves reproduce el orden falocéntrico de la cultura machista latina a través de la representación de la mujer puertorriqueña como mero partenaire del hombre, apoyándolo en su gesta insurgente a través del respeto por su investidura patriarcal y de la aceptación orgullosa de su "ética doméstica", es decir, de su consagración al sostenimiento del hogar y la prole, en tanto fuentes de "fortaleza" para la tarea heroica del hombre en el espacio público:

My name is Maria Christina

I am a Puerto Rican woman born in el barrio

Our men ... they call me negra because they love me

and in turn I teach them to be strong

I respect their ways

inherited from our proud ancestors

I do not tease them with eye catching clothes

I do not sleep with their brothers and cousins

although I've been told that this is a liberal society

I do not poison their bellies with instant chemical foods our table holds food from the earth and sun $[\ldots]$ 
I am the mother of a new age of warriors

I am the child of a race of slaves

I teach my children how to respect their bodies

so they will not o.d. under the stairway's shadow of shame

I teach my children to read and develop their minds

so they will understand the reality of oppression

I teach them with discipline... and love

so they will become strong and full of life

Esteves expone aquí esta dominación machista inherente a la propia cultura niuyorriqueña, la cual relega a la mujer al espacio cerrado del domos y circunscribe su ética al apoyo subsidiario de la praxis política masculina. Este poema despertó críticas abiertas entre las escritoras niuyorriqueñas que intentaban socavar el legado patriarcal y machista de la cultura hispánica. Entre las respuestas más difundidas se encuentra el poema-respuesta "In Response", con el que abre su poemario Y Otras Desgracias/And Other Misfortunes (1985) la poeta Luz María Umpierre, quien desde una perspectiva feminista y a través de una obra y una militancia activa contra la opresión de las mujeres latinas por su condición de género, su sexualidad y su subalternización socio-cultural, le responde directamente a Esteves negando esta representación esencialista de la condición femenina, y reafirmando enfáticamente su independencia y autonomía, en tanto mujer, respecto al hombre:

My name is not María Cristina.

I am a Puerto Rican woman born in another barrio.

Our men... they call me pushie

for I speak without a forked tongue

and I do fix the leaks in all faucets. 
I don't accept their ways, shed down from macho ancestors... (74) ${ }^{10}$

En este poema de Umpierre la mujer latina aparece como un ser autosuficiente que se yergue altivo resistiendo ahora ya no los embates asimilacionistas y opresivos de la sociedad hegemónica, sino la opresión ejercida en el seno de su propia cultura, en tanto orden patriarcal y falocéntrico ${ }^{11}$. Pero lo cierto es que si bien Esteves acepta y participa de esta cultura patriarcal, también es cierto que esta representación de la mujer no es excluyente en su poemario, sino que se integra y complementa con representaciones contrapuestas que resisten esta condición femenina subalterna y dan cuenta del complejo entramado de contradicciones que atravesaban la identidad femenina y la propia identidad niuyorriqueña en aquel contexto socio-histórico. Este entramado de contradicciones se vuelve evidente, por ejemplo, en los poemas que Esteves dedica a Lolita Lebrón, figura de la lucha independentista puertorriqueña y emblema de la mujer militante cuyo cuerpo deja de ser potencia progenitora para transformarse en un instrumento político de resistencia activa, y también en poemas como "From the Common Wealth", donde Esteves interpela y desafía ese orden falocéntrico que parecía aceptar y reafirmar en "A la Mujer Borrinqueña”:

\footnotetext{
${ }^{10}$ Pese a ser incluida en antologías de poesía niuyorriqueña Umpierre no se reconoce a sí misma a través de esta categoría identitaria, ni reconoce su adscripción a esta tradición poética. No obstante, su poética, más allá de su marcada reivindicación y activismo feminista/queer, comparte muchos de los rasgos que caracterizaron a la poesía niuyorriqueña durante las décadas del setenta y el ochenta.

11 También la poeta puertorriqueña radica en EEUU Nemir Matos-Cintrón postula durante la década del 80 una voz poética que subvierte esta identidad femenina esencialista y, especialmente, la reducción somática del cuerpo femenino a su función biológica reproductiva y su condición subalterna dentro del orden social falocrático. Los versos de poemas como "Me robaron mi cuerpo", publicado en Las mujeres no hablan asi (1981), exponen, con mayor potencia incluso que Umpierre, la violencia inherente a esta subalternización de la identidad de la mujer, duplicada en el caso de identidades LGTBQ, dentro del sistema falocéntrico vigente: "Me robaron mi cuerpo/ yo puta sanjuanera/ yo monja lesbiana/ yo mujer estéril/ [...]/ y me violaron/ porque 'en el fondo/ esto es lo que queremos/ todas las mujeres'..." (2010: 13).
} 
I reject a service role

a position I've truly hated whenever it was forced upon me

And it's true that I am a drifter, a wanderer

a gypsy whose objective in life is to travel in whole circles

that resemble the path of Venus around the Sun

I never reveled in washing clothes

or reached orgasms from dirty dishes

but I didn't mind being part of someone

who could help me to be me

with all my transcient contradictions... (49)

Como se ve aquí, la posición de Esteves no puede reducirse a la mera aceptación pasiva de su doméstico rol femenino subalterno, sino que se debate en el medio de una identidad compleja tensada en el perpetuo intersticio de su cultura hispánica patriarcal y su consciencia libertaria en el marco de una sociedad como la sociedad norteamericana de los años setenta marcada por los movimientos de lucha por los derechos civiles y por el activismo feminista.

No obstante estas diferencias que hemos marcado, hay algo que comparten las poéticas de Esteves y Umpierre y es su carácter agonístico, es decir, el reconocimiento de una figura antagónica (un enemigo) y la necesidad consecuente de confrontar esta alteridad a través de la palabra poética como instrumento de lucha, razón por la cual ambas poetas pueden ser incluidas dentro de esta tradición contestataria niuyorriqueña institucionalizada en los setenta.

\section{El cuerpo de la mulata: feminización y empoderamiento en la poesía "menor" de Tato Laviera}


Dentro de esta misma generación poética niuyorriqueña que recupera la tradición de la impotencia puertorriqueña encontramos, sin embargo, obras que transforman decisivamente esta politicidad agonística y el orden falocéntrico que la sustenta, como, por ejemplo, en la poética del niuyorriqueño Tato Laviera, en cuyos poemas la tradición puerto/niuyorriqueña de la impotencia y el macho castrado cede lugar, en cambio, a la emergencia preponderante del cuerpo femenino, específicamente el cuerpo de la mujer mulata, como significante capaz de constituirse en la base de una identidad cultural niuyorriqueña y al mismo tiempo en la fuente de un política contradiscursiva y subversiva frente a los proceso de asimilación cultural y opresión social. En la poesía de Laviera nos enfrentamos con una proliferación de cuerpos mulatos empoderados como fuente y fundamento de la resistencia y superación de las fuerzas asimilacionistas y opresivas de la sociedad hegemónica. Este empoderamiento del cuerpo niuyorriqueño se operará, fundamentalmente, en la poética de Laviera a través de la recuperación de la tradición cultural afro-antillana y su dimensión fruitiva. El desplazamiento operado por la poética lavieriana dentro de esta tradición implicó reposicionar el género femenino como fuente de afianzamiento y liberación de la identidad cultural niuyorriqueña respecto a su condición subalterna representada, como hemos visto, por medio de la figura del macho castrado e impotente. Este corrimiento del género desde el cual se enuncia no implica, como hemos esbozado en el inicio de este trabajo, una escritura femenina sino una escritura feminizada, esto es, una escritura poética que deposita en su devenir femenino gran parte de su potencia subversiva. Como señala acertadamente Nelly Richard, no es la identidad sexual/biológica de la figura autoral la que garantiza la "feminidad" de un texto sino su potencia subversiva en tanto literatura menor: 
Más que de escritura femenina, convendría entonces hablar — cualquiera sea el género sexual del sujeto biográfico que firma el texto- de una feminización de la escritura: feminización que se produce cada vez que una poética o que una erótica del signo rebalsan el marco de retención/contención de la significacion masculina con sus excedentes rebeldes (cuerpo, libido, goce, heterogeneidad, multiplicidad, etc.) para desregular la tesis del discurso mayoritario. Cualquier literatura que se practique como disidencia de identidad respecto al formato reglamentario de la cultura masculino-paterna; cualquier escritura que se haga cómplice de la ritmicidad transgresora de lo femenino-pulsional desplegaría el coeficiente minoritario y subversivo (contradominante) de lo "femenino". Cualquier escritura en posición de descontrolar la pauta de la discursividad masculina/hegemónica compartiría el "devenir-minoritario" (DeleuzeGuattari) de un femenino que opera como paradigma de desterritorializaci6n de los regímenes de poder y captura de la identidad normada y centrada por la cultura oficial. (132)

La obra de Tato Laviera no representa una escritura femenina en el sentido obvio de que su autor es un hombre y no una mujer, pero también en el sentido en que su inscripción autoral dentro del canon (el de la tradición niuyorriqueña institucionalizada por Algarín) se opera desde esta posición masculina y no desde ese margen signado por la condición socio-cultural de la mujer dentro de las relaciones de poder falocráticas del canon, sistema con el cual, como señala Richard, el hombre puede relacionarse como

parte solidaria y activa de la tradición (hasta para quebrarla bajo el estilo de la "guerra heroica contra un precursor" librada por el hombre escritor) y no, como es el caso de la mujer, del sentirse excluida por ella, o bien conducida a "la servidumbre, el discipulado, el mimetismo" por el peso de 
CATEDRAL TomAdA: Revista de crítica literaria latinoamericana / Journal of Latin American Literary Criticism

Poesía y género: de la tradición puertorriqueña del macho impotente a la feminización subversiva niuyorriqueña

la autoridad canónica de la tradición oficial cuando es vivida como ajena, enajenadora. (Richard 135)

Esta salvedad no impide, como señala la propia Richards y como intentamos demostrar en este trabajo, que el autor no pueda operar una feminización de su escritura desde su posición masculina dentro del canon, como es el caso, precisamente, de la poesía de Laviera. Coherentemente con esta teoría de la feminización una escritura feminizada no presupone una mujer-autor, así como tampoco ésta garantiza una escritura feminizada, tal como veíamos, por ejemplo, en el caso de Sandra María Esteves. Es, precisamente, esta feminización contra-hegemónica la que vibra en la poética de Tato Laviera como instrumento político de resistencia en su condición de literatura menor.

Las literaturas menores eran, para Deleuze y Guattari (1998), aquellas en las que una lengua menor operaba dentro de otra mayor, configurando así un “devenir otro" de la lengua, una extranjerización de la propia lengua. Se trata más que de un tipo de literatura, de un uso de la literatura, de un uso de la lengua por parte de la literatura. Deleuze enfatiza este uso como la potencia de las literaturas menores cuando señala que "una literatura menor no se define por una lengua local que le sería propia, sino por un trato que inflige a la lengua mayor" (80). Estas inflexiones minoritarias subvierten las culturas mayores sobre las que se sitúan operando desde dentro y a través de sus sistemas culturales y lingüísticos, a los que se desestabiliza por medio de la extranjería inasimilable de su devenirotro: "una especie de lengua extranjera, que no es otra lengua, ni un habla regional recuperada, sino un devenir-otro de la lengua, una disminución de esa lengua mayor, un delirio que se impone, una línea mágica que escapa del sistema dominante" (Deleuze, Crítica 16). Este devenir subversivo de la poética menor de Tato Laviera adopta en gran parte de su obra el carácter de una feminización de la identidad niuyorriqueña, proceso que dialoga directa y polémicamente con esta 
tradición puerto/niuyorriqueña de la impotencia de la que hemos venido hablando $^{12}$.

La resistencia y transgresión de la poética lavieriana frente a las fuerzas asimiladoras y marginalizantes de la sociedad hegemónica se fundan, en principio, en la potencia contradiscursiva y subversiva del propio cuerpo. Pero no se trata de cualquier cuerpo, sino del cuerpo mulato. La potencia subversiva de la lengua de Laviera, del cuerpo de esta lengua en su doble naturaleza somática y vocal (soma/sema) posee una identidad fuertemente marcada por la cultura afroantillana. Es, precisamente, esta identidad afro-antillana la que caracteriza la concepción de Laviera respecto a la negritud de esos cuerpos subversivos e insurrectos que dominan en sus poemas como instrumentos de resistencia frente a las fuerzas opresivas de lo social. Un ejemplo de esta nueva concepción y representación del cuerpo se encuentra en la segunda sección del primer poemario de Laviera, La Carreta Made a U-turn (1979), titulada "Loisaida Streets: Latinas Sing", y en la cual el escenario continúa siendo, como en los demás poetas de la primera generación niuyorriqueña, las calles del barrio puertorriqueño del Lower East Side y sus marcas de marginalización social, pero ahora el foco en lugar de ubicarse en el entorno hostil y degradado se ubica, en cambio, en el canto de las latinas. Al igual que con el canto de las sirenas en el poema homérico, en el poemario de Laviera el canto de la latinas se vuelve una fuerza de atracción irresistible cuya sensualidad y eroticidad atrae a la voz poética permitiendo el desplazamiento desde el tono de rabia y denuncia hacia el canto y el goce de esos cuerpos niuyorriqueños que al tiempo que son relegados socialmente nunca pierden, sin embargo, su potencialidad fruitiva, esto es su capacidad de gozar, de ser gozados, y especialmente su capacidad de transformar estas prácticas sensuales y somáticas en núcleos de resistencia frente a la marginalidad y subalternización.

\footnotetext{
${ }^{12}$ Este carácter menor de la obra de Tato Laviera no se reduce tan sólo a esta feminización de su escritura sino que se configura también por medio del interlingüismo, la performatividad y la intersticialidad de sus formulaciones identitarias. Sobre esta politicidad menor de la poética lavieriana ver: López (2014).
} 
Los títulos de los poemas que componen esta segunda sección de $L a$ carreta abundan en alusiones sensuales centradas mayormente en figuras femeninas. El cuerpo femenino se vuelve aquí no sólo objeto de deseo y exaltación sino, principalmente, fuente de goce y provocación lasciva, propulsión al movimiento y la danza, una conjunción de cuerpos que bailan al ritmo de las tonalidades afro-antillanas del barrio boricua. El segundo poema se titula, por ejemplo, "a message to our unwed women", e indaga en la potencialidad que entraña la sexualidad y el cuerpo femenino. Por un lado, aparece la figura de la mujer joven embarazada sin haberse casado, figura que se vuelve un símbolo de las miserias inherentes a cierta cultura machista imperante aún en la comunidad niuyorriqueña: el dolor profundo, las lágrimas, el sufrimiento y la vergüenza de la joven no son producto de su embarazo sino de la incriminación social y pública a la que se ve sometida por la comunidad circundante; pero entonces, repentinamente, la figura femenina del poema comprende y reconoce su cuerpo y la vida que lleva dentro ("i will have him, coño,/ because i want him/ because $\mathrm{i}$ feel this breast/ of life" (37) y una suerte de epifanía se apodera de su ser mudando el dolor y las lágrimas en regocijo y orgullo por la vitalidad que entraña este cuerpo:

tears suddenly stopped

in the most majestic manner

that pleased only yourself

you quietly said:

"i am now a true woman

my child will not be called

illegitimate

this act was done with love

with passion 


\section{[...]}

the sun radiated

the streets became alive

"to give birth A LA RAZA

is the ultimate that $\mathrm{i}$ can

ever give (37)

Este reconocimiento y ponderación del cuerpo femenino a partir de su función genesíaca no reduce, como podría parecer en una lectura lineal, la identidad femenina ni su corporalidad a la función maternal, cuestión controversial que como vimos promovió álgidas polémicas en el seno de la tradición nuyorriqueña. En la Poética lavieriana la mujer ocupa un rol determinante como paradigma del complejo entramado de tácticas políticoculturales que esta poesía despliega a partir de una concepción del cuerpo como fuente de conocimiento y fruición, núcleo privilegiado de una epistemología corporal que encuentra en la danza su máxima expresión, en tanto instancia de encarnación de los poderes disruptivos de la ritmicidad sincopada de las culturas populares afro-antillanas. En La Carreta Made a U-turn el reconocimiento del propio cuerpo, de la propia sexualidad y del potencial genesíaco del cuerpo femenino, se transforma en el valor máximo y elude así toda censura social: es el yo descubriendo las potencias que encarna su cuerpo, un cuerpo capaz de gozar, ser gozado y de alumbrar una nueva vida. La perspectiva del poema pasa, de este modo, del imperio de la miseria social del gueto al descubrimiento personal del cuerpo como núcleo de potencia y resistencia. El valor progenitor de la mujer es exaltado por Laviera a partir de su potencia vital frente a las fuerzas tanáticas que oprimen su subjetividad subalterna, pero al mismo tiempo esta potencia vital trasciende el espacio privado y cerrado del domos para expandirse en tanto praxis política contra-hegemónica por medio de su articulación con la fruición y el erotismo. Así, por ejemplo, en poemas como "A sensitive bolero in 
CATEDRAL TomAdA: Revista de crítica literaria latinoamericana / Journal of Latin American Literary Criticism

Poesía y género: de la tradición puertorriqueña del macho impotente a la feminización subversiva niuyorriqueña

transformation (for anne sexton)", donde Laviera introduce la figura de la poeta norteamericana Anne Sexton y su voz moduladora de las angustias y padecimientos de las mujeres en los márgenes, la voz poética da un paso definido hacia la dimensión somática y fruitiva de la identidad niuyorriqueña, y por eso el poema en lugar de centrarse en el despojo y la denuncia lo hace, en cambio, en el potencial subversivo encarnado por el propio cuerpo.

"A sensitive bolero in transformation" comienza con la imagen del cuerpo femenino, más específicamente, con sus órganos erógeno-maternales ( "se no/ se no/ breast/ breast”), e inmediatamente apela a la potencia erotizante de este cuerpo: "se sensual". La aliteración que atraviesa todo el poema insiste en la potencia del sema "seno", el cual en una suerte de calambur es invertido numerosas veces para volverse un "no se", o por medio del hipérbaton "se no". Este par estructura todo el poema y establece la tensión constitutiva de la poética de Laviera, por un lado la insoslayable y omnipresente situación de degradación y marginalización que tiñe el espacio social de la comunidad (y con mayor intensidad a las mujeres merced a su doble subalternidad dada su condición de género), lo que constituía el punto de partida de esta tradición poética contestataria; y por otro lado, emerge el potencial subversivo que late en los cuerpos de estos sujetos marginados: esta es la tensión entre el "no saber", o incluso el "no ser", y el "seno", fuente de fruición y vida, núcleo de resistencia frente a la imposición social que relega estos cuerpos a la miseria y la subalternidad.

El poema, por tanto, se halla tensado entre estas dos fuerzas contrapuestas: la sujeción de estos sujetos a los márgenes y el descubrimiento del cuerpo como instrumento de resistencia y de goce, de movimiento y elusividad. Ambas fuerzas se entrecruzan y oscilan permanentemente aunque finalmente es la última la que prevalece. Tras la apelación "se sensual”, el poema continúa con esta dualidad constitutiva: 
breast

hard

duro

mistreated

maltratado

manoseado

se no

seno no se......... han abierto

se están

desarrollando

buscando

la fuerza

dios mío

la fuerza

de crear

de despojar ¡leche! ¡leche! (38)

El seno en este poema de Laviera es a la vez "seno encarcelado" y "seno suave", "maltratado" y "sensual", "manoseado" y "orgánico". El seno se vuelve un símbolo del intersticio que domina y define la realidad niuyorriqueña, una identidad tensada entre dos extremos en permanente pugna y resignificación, una lucha que Laviera resuelve en su poesía a través del amor, entendido éste como la realización del encuentro, como la fusión inmoderada y confusa de lo heterogéneo, como el spanglish, esa lengua promiscua que se introduce en las otras con lascivia, ejerciendo cópulas desnormatizadas, haciendo caso omiso a la gramática, estableciendo una nueva gramática alrededor del deseo. El seno suave, sensual y orgánico, opuesto al seno maltratado y encarcelado, el seno que es "la 
fuerza de crear”, es para Laviera, el seno de raíz antillana, el seno caribeño: “... el jugo that juices the softest flow/ inside the veins/ of my heart -my/ definition of/ browness" (38-39). De allí que el poema que cierra esta sección de La carreta sea "the congas mujer", poema en el cual Laviera da cuenta, precisamente, de este nuevo cuerpo niuyorriqueño liberado ahora a través de su identidad fruitiva y erógena, expresada por medio del ritmo liberador de las congas:

a new woman was born!

her outstretched hands

carried the echoes

of madness to far away ears

[...]

the ultimate despojo of oppression released

machismo and respect confronted each other

the sound has been ignited!

the motor running at great speed!

hand-powered attitudes driving powerfully!

driving onto the physical self!

destroying it, constructing ...

a new woman! a new woman...

she shouted, and danced and cried openly

without any hesitation

without any fear

making everyone deal with her

a new woman! a new woman! (49) 
El tono exclamativo del poema celebra la emergencia de esta nueva identidad femenina que "lleva el eco de la locura a oídos lejanos", repeliendo así la insanidad de la opresión del cuerpo dentro de la sociedad patriarcal hegemónica, y asentando su resistencia emergente en la potencia fruitiva de su cuerpo liberado, libre ahora del "despojo" y del "machismo". De este modo, las exclamaciones, repeticiones, el polisíndeton y las anáforas construyen en el poema la aceleración de un ritmo poético que da cuenta de este movimiento gozoso a través del cual Laviera expresa la potencia vital de este nuevo cuerpo femenino emancipado. Esta liberación es experimentada cinéticamente por medio del ritmo acelerado y por medio de la enunciación concatenada de esta subjetividad que "grita, baila y llora abiertamente/ sin dudar", cuya materialidad somática emerge como un "motor corriendo a toda velocidad!" y que eleva el tono para concluir gritando a viva voz la celebración de su figura de "mujerconga", símbolo de la integración fruitiva de esta cultura somática y rítmica de raíz antillana.

Ahora bien, esta identidad afro-antillana corre el riesgo de entrar nuevamente en el terreno de los esencialismos. Esta esencialización de la identidad negra poseería uno de sus discursos más extendidos en la construcción de una imagen del "negro" que reduce esta identidad a su pura corporalidad, reproduciendo así el imaginario somático (o "cuerpo imaginario" en términos de Gatens $^{13}$ ) sobre el mismo erigido. Este imaginario del cuerpo negro esencializa su identidad cultural a partir de su pura materialidad, por ejemplo, por medio del tópico de la sensualidad y el erotismo del cuerpo lujurioso de la mujer mulata junto con la hipersexualidad asociada a esta figura. Estos procesos de esencialización fueron descriptos por la crítica, por ejemplo para el caso del

\footnotetext{
${ }^{13}$ Gatens concibe el "cuerpo imaginario" en los siguientes términos: "Un cuerpo imaginario no es simplemente un producto de la imaginación subjetiva, la fantasía o el folklore. El término 'imaginario' será usado con un sentido laxo pero, no obstante, también técnico como referencia a esas imágenes, símbolos, metáforas y representaciones que contribuyen a construir formas diversas de subjetividad. En este sentido, me interesan los (a menudo inconscientes) imaginarios de una cultura específica: esas imágenes prestablecidas y símbolos a través de los cuales damos sentido a los cuerpos sociales y los cuales determinan, en parte, su valor, su estatus y cuál debe ser su presunto tratamiento adecuado" (1996: xviii, mi traducción).
} 
CATEDRAL TomAdA: Revista de crítica literaria latinoamericana / Journal of Latin American Literary Criticism

Poesía y género: de la tradición puertorriqueña del macho impotente a la feminización subversiva niuyorriqueña

negrismo poético hispanoamericano, como instancia de reproducción de estereotipos sexuales y genéricos sobre el cuerpo femenino (Kutzinski 1993), pero también como instancias de representación de la identidad subalterna del negro en tanto corporalidad reificada a partir de su materialidad productiva, tanto sexual como laboral. Esta reificación implicaba al mismo tiempo, tal como señala Julio Ramos a propósito de los discursos anti-esclavistas del siglo XIX, la construcción de un objeto de deseo del que dependía en gran medida la subjetividad racional que narrativizaba este cuerpo y evidenciaba, por medio de esta relación, su construcción mutua en tanto sujeto cognoscente y objeto cognoscible:

la reificación del esclavo en el lugar del cuerpo -en el lugar del trabajo, del fundamento productivo de la sociedad, de la alimentación, de la sexualidad y de la reproducción misma- conlleva, para esa mente que se distancia del cuerpo, la dependencia (y el deseo) del objeto mismo de su abyección. (Ramos 229-30)

Pero, como señala Andrea Morris (2008), en la poesía negrista de autores como Luis Palés Matos esta sexualidad y corporalidad afro-antillana funcionan, en verdad, como potencias contradiscursivas y subversivas frente a las construcciones hegemónicas de la identidad nacional, identidad que en el caso de Puerto Rico se construía sobre un patrón claramente blanco y falocéntrico. Por otro lado, y en conjunto con esta función contra-hegemónica, la poesía palesiana (al igual que la de Tato Laviera) recupera el cuerpo negro como instancia de transgresión del orden cultural dominante por medio de la validación de una epistemología alternativa. Si bien, tanto el negrismo hispanoamericano como el movimiento de la negritude en el Caribe francófono, cayeron en algún momento en estancamientos esencialistas, no es menos cierto, como señala Alejandro de Oto, que en muchos otros casos se eludió esta reificación transformando al cuerpo 
mulato en el espacio propicio para potenciar su emancipación por medio de una política insurgente y descolonizante:

Con frecuencia se ha leído que la negritude establecía marcas esencialistas en las que quedaba atrapada. Por el contrario, si uno de los efectos poéticos y retóricos ha sido ese, también, otros de los mismos efectos poéticos y retóricos ha sido el de la idea del cuerpo como promesa y como posibilidad, como apertura. (de Oto 158)

Claramente, este es el caso de obras como la de Tato Laviera, cuya poesía no sitúa su lugar de enunciación desde la perspectiva exotista del voyeur occidental, no por cierto por el hecho de que el propio Laviera sea un mulato, sino porque en su obra el cuerpo y la voz del negro se integran dentro de una tradición cultural afro-antillana que instaura al cuerpo no como símbolo deshistorizado de exaltación, sino como fuente experiencial privilegiada. Esta nueva base epistemológica supone un marco alternativo para el reconocimiento de la "negritud" como corporalidad, uno en el cual ésta ya no es la reproducción de su materialidad productiva dentro de un sistema de sometimiento y explotación, sino que, por el contrario, el cuerpo se vuelve en este marco epistemológico fuente principal de conocimiento a través de la potencialidad de sus fruitivas experiencias sensoriales y, consecuentemente, la base de la configuración de una identidad, ya no depurada a través de la homogeneidad, sino sostenida a través de la promiscua lascivia de sus sucesivas y múltiples con-fusiones. Todos estos sentidos somáticos explotados por la poética de Laviera: gusto, olfato, tacto, oído y vista, se configuran en instancias privilegiadas del conocimiento que este sujeto poético desarrolla en su trayectoria y configuran la base de una praxis cultural centrada alrededor del goce y la propensión hacia el contacto y fusión con el otro. El carácter paradojal de esa construcción discursiva de la otredad negra, como deseo abyecto de la mirada occidental, es subvertida en la poesía de Laviera, en principio, por la anulación de esta escisión entre la voz poética y su objeto de 
deseo, y en segundo lugar, y fundamentalmente, por la construcción de una experiencia en la que el cuerpo se erige como espacio de encuentro y profusión con el otro, un espacio indeterminado en el que los contactos promiscuos y heterogéneos con el otro hacen emerger una cultura del goce por la hibridez. Así la reificación del cuerpo es transformada en la poesía de Laviera en su contrario: el cuerpo se vuelve ahora espacio de comunión y confusión heterogénea, se vuelve la base privilegiada de la constitución de una nueva identidad intersticial, híbrida y múltiple.

Aquí se halla entonces la base de la potencia contradiscursiva de esta nueva poética niuyorriqueña en la obra de Tato Laviera. Se trata de la fuerza de una lengua que se expande por medio de su reterritorialización somática, una potencia que emerge en esta nueva corporalidad de raíces antillanas, como en el poema "santa bárbara" donde la potencia extática de la experiencia religiosa afroantillana se expresa, precisamente, a través del cuerpo portentoso de la mujer, una potencia desbordante que repone así la pujanza excesiva de su feminidad:

... pero había algo, y dolores se despojó

como una princesa taína, su cuerpo desnudo

con esa fuerza, dios mío, con esa fuerza,

esa fuerza, esa fuerza, esa fuerza que

rompe la rapidez del viento

y me hace sentir sudor

y me hace escupir lágrimas

alborotadas (76-77)

Y esta potencia subversiva emerge la mayor parte de las veces a través del cuerpo de la mujer mulata. Es en esta confluencia de la dimensión fruitiva y 
sensual de la sexualidad femenina con su potencial genesíaco, donde el cuerpo femenino negro se vuelve fuente del nuevo paisaje niuyorriqueño y base de su liberación.

Vemos, por tanto, como la poética desplegada por Tato Laviera en el seno de la tradición niuyorriqueña (y desde un margen extraterritorial y diaspórico en la propia tradición puertorriqueña) configura una escritura feminizada que instaura en este desvío singular respecto al canon falocéntrico de la tradición, la posibilidad de superar el agonismo contestatario de la primera generación poética niuyorriqueña por medio de nuevas tácticas políticas que encuentran en esos márgenes constituidos por el cuerpo como objeto de opresión y por lo femenino en tanto género de la subordinación, nuevos instrumentos de resistencia para enfrentar los dispositivos sociales de asimilación cultural y subalternización social. La feminización que introduce esta poética en el seno de los cánones puerto/niuyorriqueños y sus lógicas falocráticas de la impotencia subvierte, de este modo, el déficit originario que atrapaba a esta identidad cultural entre la eterna carencia de una soberanía nacional y el imaginario estigmatizante de su hibridismo deficitario, y lo hace, justamente, apelando a la potencia transgresiva de lo femenino, a esa pulsión desbordante anclada en el cuerpo femenino que lejos de volverse la huella lacerante de la castración se convierte en el instrumento pujante de la fruición y la resistencia. Señalaba Nelly Richard a propósito de la escritura femenina y su relación con el canon, que

la relación de la mujer con el sentido no es nunca total ya que parte de una inadecuación: la que la hace sentirse extraña (extranjera) al pacto de adhesión y cohesión sociales que sella la autoidentidad a través de su lengua del consenso socio-masculino en relación con el cual la mujer está siempre de menos (lo femenino como déficit simbólico) o de más (lo femenino como excedente pulsional). (139) 
CATEDRAL Tomada: Revista de crítica literaria latinoamericana / Journal of Latin American Literary Criticism

Poesía y género: de la tradición puertorriqueña del macho impotente a la feminización subversiva niuyorriqueña

$\mathrm{Y}$ es, precisamente, esta inadecuación visceral de lo femenino lo que le permitió a la poesía de Tato Laviera instaurar ese entremedio inasimilable que constituye la cultura e identidad niuyorriqueñas como el espacio privilegiado para la emergencia de una poética capaz de transformar la potencia desbordante del cuerpo, el goce y la feminidad, en ese "ardid supremo" contra los poderes hegemónicos que vislumbraba Arnaldo Cruz-Malavé en la pregunta que abría este trabajo, un arma a través de la cual la poesía niuyorriqueña logró empoderar, consecuente y magistralmente, aquello que no era, en su principio, sino pura impotencia.

\section{Bibliografía}

Algarín, Miguel. Survival Supervivencia. Houston: Arte Público Press, 2009.

Algarín, Miguel y M. Piñero. Nuyorican Poetry: An Anthology of Puerto Rican Words and Feelings. Nueva York: Morrow, 1975.

Anderson, Benedict. Comunidades imaginadas. México: Fondo de Cultura Económica, 1993.

Barradas, Efraín. Partes de un todo: ensayos y notas sobre literatura puertorriqueña en los Estados Unidos. San Juan: Universidad de Puerto Rico, 1998.

Bhabha, Homi. Nation and narration. Londres: Routledge, 1990.

The Location of Culture. Londres: Routledge, 1994. 
Castoriadis, Cornelius. La institución imaginaria de la sociedad. Buenos Aires: Tusquets, 2007.

Cruz-Malavé, Arnaldo. «Towards an Art of Transvestism: Colonialism and Homosexuality in Puerto Rican Literature» en ¿Entiendes?: Queer Readings, Hispanic Writings. Eds. Bergmann L. y P. Smith, Durham: Duke UP, 1995. 137-67.

de Oto, Alejandro. «Aimé Césaire y Frantz Fanon. Variaciones sobre el archivo colonial/descolonial»»" en Tabula Rasa, 15, 2011. 149-69.

Deleuze, Gilles. Crítica y clínica. Barcelona: Anagrama, 1996.

Deleuze, Gilles y F. Guattari. Kafka. Por una literatura menor. México: Era, 1998.

Díaz Quiñones, Arcadio. El arte de bregar y otros ensayos. San Juan: Callejón, 2000.

Duany, Jorge. The Puerto Rican Nation on the Move: Identities on the Island and in the United States. Chapel Hill: University of North Carolina Press, 2002.

Esteves, Sandra María. Yerba Buena. Nueva York: Greenfield Review Press, 1980.

Gatens, Moira. Imaginary Bodies. Ethics, power and corporeality. Nueva York: Routledge, 1996.

Grosfoguel Ramón, F. Negrón-Muntaner y C. Georas (eds.). Puerto Rican Jam: Rethinking Colonialism and Nationalism. Minneapolis: University of Minnesota Press, 1997.

Guha, Ranajit. «Preface» en Selected Subaltern Studies. Eds. Guha R. y G. Spivak, Oxford University Press, Nueva York, 1988.

Kogan, Liuba. «La insoportable proximidad de lo material: cuerpos e identidades en las ciencias sociales» en Debates en Sociología, 32, 2007. 9-18.

Kristeva, Julia. La révolution du langage poétique: L'avant-garde à la fin du XIXe siècle. Lautréamont et Mallarmé. Paris: Seuil, 1974. 
CATEDRAL TomAdA: Revista de crítica literaria latinoamericana / Journal of Latin American Literary Criticism

Poesía y género: de la tradición puertorriqueña del macho impotente a la feminización subversiva niuyorriqueña

Kutzinski, Vera. Sugar's Secrets: Race and The Erotics of Cuban Nationalism.

Charlottesville: University of Virginia Press, 1993.

Laviera, Tato. La Carreta Made a U-turn. Houston: Arte Público Press, 1979.

López, Alejo. «Activismo, política y subversión en la literatura niuyorriqueña: del programa poético-político de Miguel Algarín a la poética menor de Tato Laviera» en Ciencia Política, 9 (1), 2014. 19-47.

Marqués, René. «En la popa hay un cuerpo reclinado» en Cuentos Puertorriqueños de Hoy. Ed. René Marqués, San Juan: Club del libro de Puerto Rico, 1959. 129-146.

Marqués, René. El puertorriqueño dócil y otros ensayos (1953-1971). Río Piedras: Editorial Antillana. 1977 [1960].

Matos Cintrón, Nemir. Las mujeres no hablan así. San Juan: Editorial Atabex, [1981] 2010.

Morris, Andrea E. «Performing Dance/Writing Dance: Embodiment and the Question of Female Agency in Afro-Antillean Poetry and Culture» en Revista de Estudios Hispánicos, 42, 2008. 391-414.

Pedreira, Antonio S. Insularismo: Ensayos de interpretación puertorriqueña. San Juan: Biblioteca de Autores Puertorriqueños, 1934.

Ramos, Julio. «Cuerpo, lengua, subjetividad» en Revista de Crítica Literaria Latinoamericana. 19 (38), 1993. 225-37.

Reisz de Rivarola Susana. Voces Sexuadas: Género y Poesía en Hispanoamérica. Lérida: Asociación Española de Estudios Literarios Hispanoamericanos, 1996.

Richard, Nelly. «¿Tiene sexo la escritura?» en Debate Feminista, 9 (1), 1994. 127-139.

Ríos Ávila, Rubén. La raza cósmica del sujeto en Puerto Rico. San Juan: Callejón, 2002.

Silverman, Kaja. Male Subjectivity at the Margins. Nueva York: Routledge, 1992. 
Sommer, Doris. Foundational Fictions: The National Romances of Latin America. Berkely: University of California Press, 1991.

Turner, Bryan. «Los avances recientes en la teoría del cuerpo» en REIS, 68, 1994. 11-39.

Umpierre, Luz María. Y otras desgracias/ And Other Misfortunes... Bloomington Indiana: Third Woman Press, 1985. 